\title{
PENGARUH BAHASA ARAB TERHADAP IDENTITAS SOSIO- KULTURALDAN KEAGAMAAN MASYARAKAT KOPTIK DI MESIR
}

\author{
Yoyo \\ yoyo@bsa.uad.ac.id \\ Bahasa dan Sastra Arab \\ Universitas Ahmad DahlanYogyakarta
}

\begin{abstract}
In general, Arabic is the official language of the Arab states. However, at the beginning of its contact with non-Arab societies, this language - that is always associated as the language of Islam - was not easily accepted by non-Muslims. One of them is Coptic community, the native of Egyptian people who are Christians and speak Coptic language. The spread of the Arabic language was a serious challenge for them both from the issue of social identity, culture, and religion. This paper attempts to elaborate the reactions and efforts made by the Coptic community on the influence of the Arabic language to their lives. In detail, the paper tries to answer research questions as follow: 1) Howwas the social and political background of Coptic community before and after the coming of Islam in Egypt? 2) How was the Islamization and Arabization process in Egypt? Did the process run concurrently or two things different from its periode? What is the influence of the Arabic language on socio cultural and religious aspects of the Coptic community? To arrive at these objectives, the author used descriptive analysis methods by reviewing previous studies related to the subject and combining it with current information. The results showed that: 1) from the socio-cultural side, Arabic has become Coptic identity that can be seen from their Arabic names and their integration as part of both in ritual and religious literature.
\end{abstract}

Keywords: Arabic Language, Language contact, Coptic language, Egypt

$$
\begin{aligned}
& \text { ملخص } \\
& \text { اللغة العربية هي اللغة الرسمية لأكثر الدول العربية ، ومع ذلك فإن هذه اللغة التى تعتبر لغة إسلامية لا يسهل }
\end{aligned}
$$

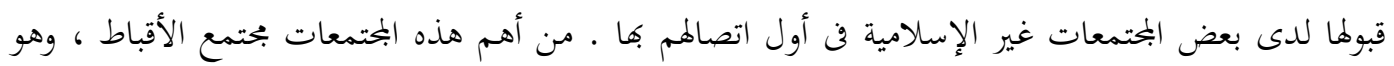

$$
\begin{aligned}
& \text { بجتمع مصري اعتنق بالمسيحية وتكلم باللغة القبطية ـ في هذا المجتمع يمثل حضور وسيادة اللغة العربية تحديات }
\end{aligned}
$$

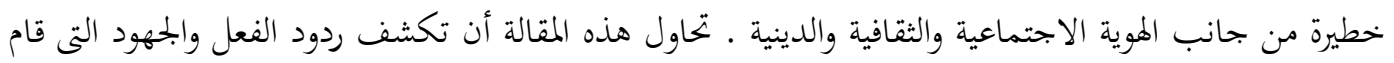

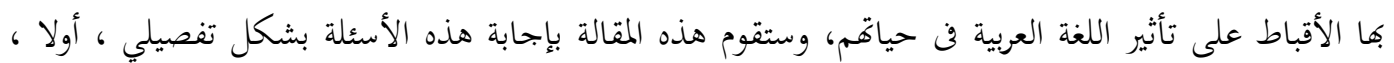

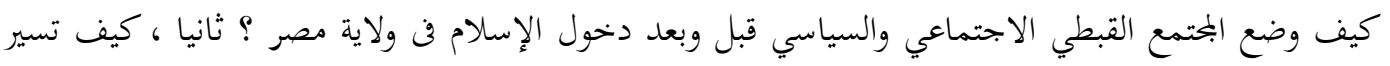

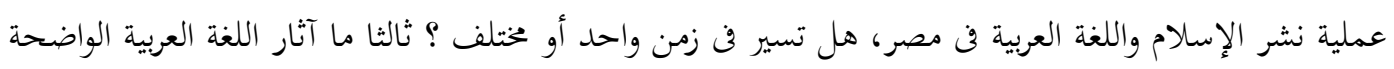

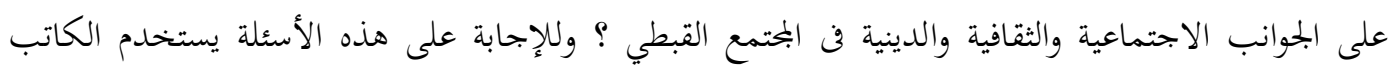

$$
\begin{aligned}
& \text { منهج التحليل الوصفي بطريقة البحث فن الدراسات السابقة المتعلقة بتلك المسائل ثم دبجها مع المعلومات المعاصرة }
\end{aligned}
$$




$$
\begin{aligned}
& \text { • وقد توصلت الدراسة إلى النتائج الآتية : أولا، من الناحية الاجتماعية والثتافية ، أصبحت اللغة العربية هوية } \\
& \text { قبطية من خلال تسمية الفرد القبطي بأسماء عربية وأصبح انتماؤهم الثقافي جزءا من الثقافة العربية فن المجتمع } \\
& \text { المصري ـ ثانيا ، من الناحية الدينية حلت اللغة العربية محل اللغة القبطية في الشعائر والأناشيد الدينية. } \\
& \text { الكلمات المفتاحية : اللغة العربية ، الاتصال اللغوي، اللغة القبطية ، مصر . }
\end{aligned}
$$

\section{PENDAHULUAN}

Persepsi umum tentang kawasan Arab atau Timur Tengah adalah bahwa mayoritas masyarakatnya berbahasa Arab dan beragama Islam. Persepsi demikian ada benarnya karena sudut pandang yang digunakan adalah perspektif agamakawasan Arab sebagai tempat lahirnya agama Islam-maka wajar apabila persepsi di atas menjadi common sense tentang masyarakat dan kawasan Arab pada umumnya.

Untuk menghindari persepsi di atas, wajar apabila sebagian sarjana Barat lebih senang menggunakan istilah Timur Tengah daripada istilah kawasan Arab. Hal ini dimaksudkan bukan saja pertimbangan dari sisi geografis tetapi juga istilah tersebut dianggap mampu mengakomodir keanekaragaman masyarakat dan kultural yang terdapat di kawasan tersebut. Sebut saja E. T. Mahan umpamanya, merupakan Sarjana Barat pertama yang telah berkontribusi dalam mempopulerkan istilah Timur Tengah atau the Middle East untuk menyebut kawasan Arab yang terbagi ke dalam beberapa kawasan (Arab bagian Afrika Utara, Arab bagian Timur, Arab Teluk, dan Arab bagian Asia-Barat) (Goldschmidt Jr \& Boum, 2015). ${ }^{1}$

Salah satu dari keanekaragaman yang terdapat di kawasan Arab atau Timur Tengah yaitu hadirnya masyarakat Koptik di kawasan tersebut, Mesir khususnya. Meskipun secara sosio-kultural saat ini

1 Dalam tulisan ini penulis lebih tertarik untuk menggunakan kedua istilah tersebut secara bergantian sesuai dengan konteks penggunaannya. mereka hidup damai dengan masyarakat Muslim di Mesir, namun apabila merujuk pada sejarah awal kontak antara Koptik dengan Islam baik itu dari sisi bahasa, agama, maupun budaya telah muncul konflik sekaligus pergulatan identitas kultural dari kalangan mereka. Hal ini maklum terjadi karena masyarakat Koptik sebagai penganut Kristen telah terlebih dahulu hadir di kawasan tersebut ratusan tahun sebelum lahirnya Islam.

Artikel ini berupaya untuk menyajikan sebuah perspektif tentang urgensi bahasa sebagai identitas sebuah bangsa. Bahasa bukan saja sebagai alat untuk berkomunikasi, namun ia juga merupakan representasi identitas sebuah kelompok manusia atau bahkan sebuah bangsa. Sebagai contoh, sejarah lahirnya negara Pakistan yang memisahkan diri dari India, dilatarbelakangi oleh adanya perbedaan bahasa yang digunakan. Masyarakat Muslim di India menggunakan bahasa Urdu sebagai bahasa komunikasi dan identitas keagamaan mereka yang berbeda dengan masyarakat India yang mayoritas beragama Hindu dan berbahasa Hindi. Alasan perbedaan inilah yang kemudian menjadikan argumentsi utama masyarakat Muslim India untuk lepas dari negara tersebut dan bergabung menjadi bagian dari negara baru yaitu Pakistan dengan Urdu sebagai salah satu bahasa identitas kultural dan agama yang ada (Rahman, 2002).

Mencermati narasi di atas, bahasa Arab yang identik sebagai bahasa agama Islam menjadi tantangan serius bagi masyarakat Koptik sejak awal mula kehadirannya di Mesir. Masyarakat Koptik telah membangun identitas 
kultural dan agama mereka berdasarkan pada kesatuan bahasa yang digunakan, yaitu bahasa Koptik. Praktek ritual keagamaan dan bahkan Kitab Suci mereka pun (Bible) ditulis dalam bahasa Koptik. Oleh karena itu, hadirnya bahasa Arab di tengah-tengah masyarakat Koptik menjadi tantangan serius dan dianggap dapat menggerus identitas kultural juga tradisi keagamaan mereka yang telah mapan.

Secara lebih spesifik, artikel ini mencoba menjawab beberapa rumusan masalah sebagai berikut: 1) bagaimanakah kondisi sosial dan politik masyarakat Koptik di Mesir sebelum dan sesudah masuknya Islam ke wilayah tersebut? 2) Bagaimanakah proses Islamisasi dan Arabisasi di Mesir? Apakah proses tersebut berjalan bersamaan atau dua hal yang dari sisi waktunya berbeda? dan 3) Apakah pengaruh nyata bahasa Arab terhadap aspek sosio-kultural dan keagamaan masyarakat Koptik?

Beberapa penelitian terdahulu tentang Koptik di Mesir baik dilihat dari aspek sosial-politik dan agama telah banyak dilakukan. Randall P. Henderson (2005) dalam papernya "The Egyptian Coptic Christians: the Conflict between Identity and Equality" menjelaskan tentang hubungan antara Koptik dan Muslim dilihat dari hak-hak sosial dan politik. Menurutnya, interaksi antara Koptik dengan Islam sejak awal kedatangannya ke Mesir sudah berjalan harmonis meskipun hubungan tersebut bersifat fluktutatif tergantung pada kebijakan politik yang ada. Di samping itu, Koptik di Mesir juga mengalami gejolak internal dan diwujudkan dalam bentuk reformasi Gereja utamanya ketika berhadapan dengan proses Kristenisasi baik yang dilakukan oleh Protestan atau Katolik era tahun 1950an. Dalam posisi ini menurut Henderson, Koptik lebih banyak mempertahankan aspek keyakinan dan identitas yang telah mereka yakini meskipun ada beberapa yang konversi menjadi Protestan atau Katolik.

Penelitian berikutnya yang dilakukan oleh Saad Eddin Ibrahim, dkk
(1995) dalam sebuah projek berjudul The Copts of Egypt. Meskipun data-data yang disampaikan cukup lama namun data etnografi serta laporan tentang demografi, perjuangan status sosial, politik, dan agama di Mesir disajikan sangat baik. Temuan yang sangat signifikan dari laporan penelitian tersebut salah satunya yaitu mengenai data konversi dari tahun 1988-1990 di mana terdapat sekitar 50.000 mahasiswa Koptik berpindah agama menjadi Islam. Laporan penelitian menghendaki usulan undang-undang yang mengatur persoalan konversi di mana Gereja hendaknya dilibatkan dalam proses tersebut. Di samping itu, siapa saja yang memaksakan konversi sebuah agama tertentu harus mendapatkan hukuman.

Dari aspek teologi, kajian yang ditulis oleh Bishop Gregorius (1982) dengan judul "Christianity, the Coptic Religion and Ethnic Minorities in Egypt" dengan tegas menyatakan perbedaan Koptik dengan Kristen lainnya utamanya Prostestan dan Katolik baik dilihat dari sejarah, bahasa, dan bahkan kehidupan spiritualnya. Menurutnya,- dari beberapa klaim yang ia kemukakan-, Koptik diklaim lebih spiritualis dari pada Kristen yang lain. Terakhir dari sisi bahasa, terdapat penelitian yang membahas tentang pergantian dari bahasa Koptik ke bahasa Arab yaitu paper yang ditulis oleh Jason R. Zaborowski (2008) dengan judul "From Coptic to Arabic in Medieval Egypt" di mana paper tersebut menelaah satu dokumen yang disebut Qalamun. Kajian ini utamanya membahas kapan proses Arabisasi di kalangan Koptik terjadi.

Berbeda dari penelitian sebelumnya, artikel ini berupaya mengkaji lebih dalam tentang pengaruh bahasa Arab terhadap kehidupan sosio-kultural dan juga keagamaan Koptik dengan memberikan beberapa contoh kasus yang belum terdapat di dalam penelitian sebelumnya. Termasuk dalam hal ini umpamanya tentang Injil berbahasa Koptik yang dilengkapi dengan terjemahannya dalam bahasa Arab. 


\section{HASIL DAN PEMBAHASAN}

\section{Sejarah dan Kondisi Sosial-Politik Koptik di Mesir}

Sebelum Islam masuk ke Mesir, penduduknya dikenal dengan sebutan Copt, berasal dari bahasa Yunani Aigyptos dan bahasa Arabnya Qibth atau قبط, yaitu sebutan untuk penduduk asli Mesir atau pada awalnya untuk penduduk yang tinggal di sepanjang sungai Nil (Hasan, 2003). Eropa menyebut mereka dengan sebutan Jacobite, istilah Arab lainnya yaitu al-nașrōni al-ya'qūbì, al-nașrōnī alqibtī, atau secara kolektif disebut alya'āqibah (Armanios, 2011). Sekarang sebutan Koptik ini menjadi istilah khas bagi penganut Kristen Mesir yang masih mempertahankan keyakinan agama mereka di tengah mayoritas Muslim Mesir. Selain di Mesir, terdapat komunitas Koptik lainnya seperti di Nubia, Sudan, Etiopia, Kenya, Nigeria, Uganda, Afrika Selatan, Jordan, Israel, Libanon, Iran, dan Kuwait (Gregorius, 1982).

Bahasa Koptik itu sendiri merupakan bahasa resmi penduduk Mesir kuno. Bahasa ini memiliki tiga bentuk utama, yaitu: 1) hieroglyphic script, "tulisan sakral" digunakan oleh para seniman untuk melukis di dinding gereja ${ }^{2}$ atau makam; 2) hieratic script, "tulisan para imam/pastur" biasanya digunakan untuk penulisan undang-undang negara, keputusan para raja, dan juga perjanjian komersial; dan 3) demotic script, yaitu tulisan orang awam yang digunakan

\footnotetext{
${ }^{2}$ Salah satu seniman terkenal Koptik
} yang telah berjasa melukis di dinding-dinding gereja Koptik yang terdapat di Kota Kairo Lama (al-Mișra al-Qadīmah), adalah Yuhanna al-Armani. Yuhanna sendiri bukanlah seorang Koptik namun seorang keturunan Armenia yang hidup dan tumbuh besar di lingkungan Koptik kemudian mengabdikan dirinya pada seni lukis Koptik. Ikon-ikn yang dilukis oleh Yuhanna seperti gambar Maryam, Malaikat, dan Tokoh-tokoh sentral dalam tradisi Kristen Koptik. Gambar-gambar tersebut diberi keterangan dalam bahasa Koptik dan Arab(Jirjis, 2008). dalam kehidupan mereka sehari-hari khususnya untuk surat yang bersifat pribadi. Pada saat Koptik memeluk Kristen dan ingin menerjemahkan Kitab Suci dari bahasa Yahudi dan Yunani ke dalam bahasa Mesir, yaitu Koptik ditemukan beberapa kesulitan dikarenakan perbedaan karakter dan huruf. Oleh karena itu, bahasa Koptik kemudian mengadopsi sebagian huruf Yunani. Sejak saat itulah sejarah bahasa Koptik dimulai, yaitu sejak terjadinya Kristenisasi masyarakat Mesir dan adopsi sebagian

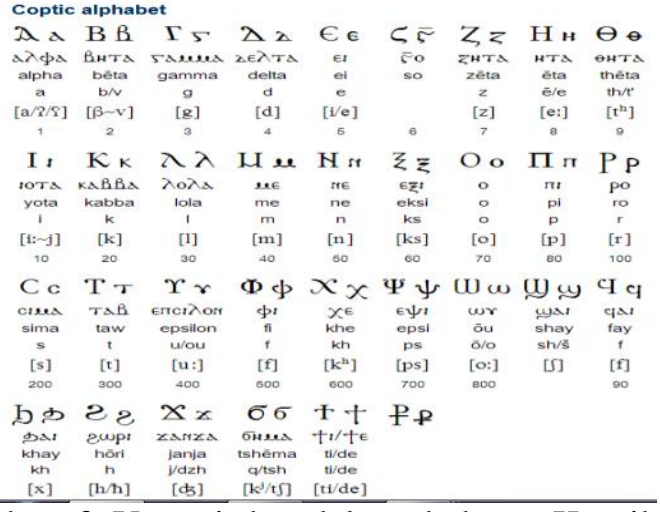

huruf Yunani ke dalam bahasa Koptik (Gregorius, 1982).

Gambar 1. Alfabet Coptic(Sumber:

http://www.omniglot.com/writing/coptic.htm.)

Dengan demikian, kristenisasi yang terjadi di Mesir sesungguhnya telah menghapus tulisan hieroglif Mesir dan menghasilkan adopsi bahasa Koptik terhadap kosa kata Yunani. Selanjutnya, bahasa Koptik berkembang menjadi medium bagi literatur Kristen (Lewis, 1998). Saat ini, bahasa Koptik hanya digunakan oleh beberapa keluarga tertentu di Mesir yang memang masih mempertahankan tradisi leluhur mereka. Meskipun demikian, bahasa ini sudah tidak lagi diajarkan kepada anak-anak mereka karena dianggap tidak terlalu bermanfaat bagi masa depan (Mayton, 2006).

Koptik Mesir merupakan penganut Kristiani terbesar di Dunia Arab. Jumlah mereka sekitar 5 juta orang atau $10 \%$ dari keseluruhan penduduk Mesir atau 4.3 juta dari jumlah total penduduk Mesir yang 
berjumlah 84 juta jiwa. Ini artinya, dari setiap 20 orang Mesir, maka terdapat 1 orang Koptik (Ibrahim, 1995; Mohamoud et al., 2013). Mayoritas Koptik masuk agama Islam ketika bangsa Arab menaklukkan Mesir pada tahun $640 \mathrm{M}$. Maka pada akhir abad ke-10 M atau awal abad ke-11 M, mayoritas masyarakat Mesir beragama Islam (Ibrahim, 1995).

Dari sisi demografi, sebagian besar masyarakat Koptik tinggal di kota-kota urban utamanya Kairo dan Mesir bagian atas seperti Asyut, Minya, dan Luxor. Migrasi besar-besaran masyarakat Kotik terjadi pada tahun 1920-an. Mereka memilih tinggal di perkotaan dengan harapan dapat lebih dekat dengan pemerintah sehingga akan lebih aman dari sisi perlindungan (Ibrahim, 1995).

Masyarakat Koptik meliputi tiga denominasi aliran Kristen yang berbeda, yaitu Ortodoks, Protestan, dan Katolik. Hanya saja, mayoritas Kristen di Mesir beraliran Gereja Ortodoks atau Gereja Alexandria, atau lebih spesifik lagi Gereja Mesir (Ibrahim, 1996: 6). Dalam praktek spiritualnya, Koptik memiliki beberapa sikap keagamaan yang berbeda. Terdapat kelompok yang mengikuti perintah Gereja dari semua aspek kehidupan, termasuk pandangan politiknya. Namun terdapat pula kelompok Koptik yang hanya melihat Gereja sebagai lembaga spiritual dan mengabaikan aspek lainnya, seperti persoalan politik dan ekonomi. Di samping itu, terdapat pula komunitas Koptik liberal dan sosialis (Guirguis, 2012).

Penganut Koptik meyakini bahwa ajaran Kristen dibawa ke Mesir oleh Rasul Mark pada 64 M. Pada era Kaisar Diocletian pada 284 M, terjadi pembantaian besar-besaran terhadap komunitas Kristen Koptik di Mesir. Peristiwa "korban mati syahid" ini selanjutnya dikenang dan mulai diperingati sejak Agustus $284 \mathrm{M}$ sampai sekarang. Dari sisi keyakinan, Koptik Kristen dianggap menyimpang dari Kristen yang berkembang di Barat pada umumnya. Perbedaannya terletak pada keyakinan Kristen Koptik tentang penyatuan alamiah antara dimensi Ketuhanan Isa (Yesus) dan sisi kemanusiaannya yang menjadi satu keutuhan. Dua dimensi yang berbeda tetapi tidak dapat dipisahkan. Maka sejak keputusan Konsili Chalcedon pada $451 \mathrm{M}$, doktrin Kristen tentang sifat Yesus terpecah menjadi dua, yaitu Kristen Timur (Koptik) dan Kristen Barat (Henderson, 2005).

Secara umum, kondisi masyarakat Koptik jauh lebih baik daripada masyarakat Mesir yang Muslim. Hal ini dikarenakan masyarakat Koptik telah terlebih dahulu menekankan pentingnya pendidikan dengan adanya anjuran dan reformasi pendidikan yang digagas oleh Patriarch Cyril IV pada akhir abad ke-19 $M$ yang mewajibkan semua Koptik untuk melanjutkan pendidikan tinggi baik itu dalam negeri maupun luar negeri. Oleh karena itu, Koptik di Mesir terkenal dengan profesi white-collar seperti insinyur, dokter, guru, dan jabatan manajer. Meskipun demikian, pada level pegawai keamanan, keterlibatan Koptik masih sangat minim utamanya di bidang Militer. Hal ini belum dapat dibuktikan secara pasti apakah minimnya keterlibatan pada bidang tersebut karena adanya marjinalisasi dari pemerintah atau justru kurangnya ketertarikan dari kalangan Koptik sendiri terhadap pekerjaan tersebut (Ibrahim, 1995; Mohamoud et al., 2013).

Era akhir abad ke-19 M dan awal abad ke-20 M, merupakan era "golden age" bagi kehidupan sosial dan politik Koptik. Hal demikian terjadi karena pada era tersebut, merupakan era kekuasaan Muhammad Ali Pasha, sebagai tokoh pembaruan Mesir yang sedang berupaya melakukan modernisasi Mesir dengan melibatkan berbagai elemen masyarakat untuk ikut berkontribusi dalam proses modernisasi tersebut (Mohamoud et al., 2013). Termasuk dalam hal ini adalah keterlibatan kalangan Koptik dan juga kalangan Kristen umumnya dalam proses tersebut (Hourani, 1962). Pada kepemimpinan Muhammad Ali Pasha, 
terdapat sejumlah pejabat dari kalangan Koptik, seperti Mu'allim Ghali selaku pejabat pemungut pajak pemerintah, sebuah profesi yang memperlihatkan bahwa Koptik memiliki posisi penting di pemerintahan. Pada era Muhammad Ali Pasha juga, terdapat sejumlah kebijakan yang mengizinkan gereja untuk membunyikan bel, membangun gereja baru, dan memperbaiki yang lama (Elyas, 2012).

Pada saat Inggris mulai menguasai Mesir pada 1882 M, terdapat Koptik pertama yang menjadi Perdana Menteri pada 1908 M yaitu Boutros Ghali, namun kemudian ia dibunuh pada $1910 \mathrm{M}$. Berikutnya, cucunya Boutros Boutros Ghali menjadi Menteri Negara pada 1977 M dan diangkat menjadi Deputi Negara pada 1991 M. Ia menjadi Koptik yang sangat terkenal saat menjabat sebagai Sekretaris Umum PBB Periode 1992-1997 M (Chaillot, 2009).

Dari tahun 1914 sampai 1922 M, Inggris menjadikan Mesir sebagai Negara Protektorat dan pada masa tersebut yaitu tahun 1918 M lahir partai baru berhaluan nasionalis yaitu partai Wafd, berjuang untuk kemerdekaan Mesir. Pendiri partai tersebut adalah Sa'd Zaghlul (1858-1927 M) di mana ketika ia menjabat sebagai Perdana Menteri pada 1924 M, menunjuk dua Menteri dari kalangan Koptik sebagai anggota dari partai, yaitu Murqus Hanna dan Wassef Boutros Ghali. Pada tahun 1930 M, dua Koptik dari partai Wafd juga menjadi menteri yaitu Wassef Boutros Ghali dan Makram Ubaid. Ketika Ikhwanul Muslimin muncul di Mesir pada 1928 M, persatuan antara Muslim dan Kristen mulai terancam. Puncaknya, paca revolusi Juli 1952 M saat Nasser berkuasa, terjadi diaspora besar-besaran bagi kalangan Koptik ke luar negeri utamanya Amerika dan Kanada (Chaillot, 2009).

Era tahun 1970-1980 M merupakan era terberat bagi kalangan Koptik seiring dengan menguatnya gerakan Islamisme serta sulitnya untuk ikut terlibat dalam arena politik. Oleh karena itu, sebagian intelektual Koptik selalu menginginkan kembali pada situasi politik era tahun 1919-1952 M, yaitu hadirnya Partai Wafd yang mampu menampung berbagai aspirasi termasuk dari kalangan Koptik sekalipun. Rafiq Habib seorang intelektual Koptik, berharap adanya keseriusan pemerintah dalam memberikan hak-hak politik masyarakat Koptik dengan cara mengadopsi sistem politik yang lebih mengedepankan prinsip-prinsip keadilan dan kejujuran seperti yang diterapkan dalam sistem politik Barat dengan tetap menjalankan norma-norma sosial yang didasarkan pada norma dan budaya lokal (Islam) (Hatina, 2006).

Pada level institusi terkait dengan revolusi the Arab Spring yang mulai terjadi pada akhir tahun $2010 \mathrm{M}$, terdapat tiga sikap Gereja di Mesir yang berbeda. Pertama, Gereja Koptik Evangelical yang mendeklarasikan dukungannya terhadap revolusi Arab. Dalam hal ini, pendeta Sameh Moris, seorang pendeta Evangelical Koptik yang ikut turun ke Tahrir Square dan menjadi figur penting dalam demonstrasi tersebut. Kedua, Gereja Koptik Katolik yang cenderung bersikap ambigu; apakah mendukung revolusi atau tidak. Terakhir, Gereja Koptik Ortodoks sebagai gereja utama di Mesir dan merupakan komunitas Koptik terbesar di Mesir dengan sangat tegas menentang revolusi dan menyatakan dukungan mutlak bagi Mubarak. Penolakan tersebut langsung disampaikan oleh Paus Shenouda III (yang telah wafat pada 17 Maret 2012 lalu), ia menyatakan bahwa mereka (Koptik) yang terlibat dalam revolusi bukanlah bagian dari gereja (Guirguis, 2012). Alasan mengapa Koptik Ortodoks menentang revolusi sederhana, apabila revolusi berhasil maka akan terjadi tekanan pada gereja terutama pada kalangan elit gereja yang sudah sangat mapan. Hal ini juga akan menghantarkan pada restrukturisasi hirarki gereja (Guirguis, 2012).

\section{Proses Islamisasi dan Arabisasi di Mesir}


Pada abad ke-7 H, Islam masuk ke Timur Tengah dan Afrika, serta pada tahun $641 \mathrm{M}$, Mesir ditaklukkan (Henderson, 2005). Mesir pada awal masa Kekhalifahan Islam (Umar bin Khattab), merupakah sebuah provinsi Kekaisaran Bizantium. Penduduk asli Mesir merupakan penganut Kristen Koptik sebagai entitas Kristen yang berbeda dari doktrin Kristen Bizantium ketika itu. Pasukan Islam masuk ke Mesir pada tahun 639 M, dipimpin oleh Amr bin al-'Ash atas perintah dari Khalifah Umar bin Khattab. Tentara Islam terdiri dari sekitar delapan ribu pasukan kuda dan dengan mudah mengalahkan pasukan Bizantium. Pada tahun $641 \mathrm{M}$, Bizantium berupaya untuk merebut kembali Mesir namun dapat dikalahkan oleh pasukan Islam atas bantuan penduduk lokal yang menganggap bahwa penguasa Islam jauh lebih baik daripada penguasa Bizantium (Brockelmann, 1947; Marsot, 2007). Koptik Mesir ikut membantu keberhasilan tentara Muslim untuk melawan Bizantium dengan cara menyediakan properti peperangan dan juga memblokade sungai untuk memperlambat pergerakan tentara Bizantium (Mikhail, 2003).

Pada saat invasi, Kristen Koptik diperkirakan sekitar $80 \%$ dari jumlah populasi penduduk ketika itu. Bagi Koptik yang tidak mau masuk Islam maka dikenakan pajak atau jizyah. Jizyah dimaksudkan sebagai dukungan dana untuk tentara dan penyebaran Islam, atau non-Muslim boleh bergabung dalam pasukan Muslim dan dibebaskan dari pajak. Perlu dicatat bahwa para pegawai administratif pajak banyak dari kalangan Koptik. Jadi, meskipun jizyah itu ditujukan untuk kalangan non-Muslim namun para pegawai pajaknya justeru berasal dari kalangan non-Muslim (Henderson, 2005).

Proses Islamisasi tidak serta merta diikuti proses Arabisasi. Arabisasi di Mesir tidak berjalan cepat seperti yang terjadi di Suriah dan Irak. Butuh beberapa abad baru terjadi proses Arabisasi yang seutuhnya. Masyarakat Mesir dengan bahasa Koptik dan agamanya dibiarkan apa adanya dengan kewajiban membayar pajak yang jauh lebih ringan dibandingkan dengan pajak yang dibebankan pada masa Kekairasan Bizantium (Marsot, 2007). Meskipun demikian, sebagai bahasa komunikasi, bahasa Arab telah tersebar bersamaan dengan penyebaran Islam. Bahasa yang ada seperti bahasa Koptik, Syiria, Aramaik, dan Yahudi, terus mengalami kemunduran dalam penggunaannya (Hourani, 1992). Proses Arabisasi secara administratif terjadi pada Era Umayyah utama pada era Khalifah Abdul Malik bin Marwan (685-705 M). Bahasa yang digunakan untuk pelayanan publik mulai berubah, yaitu digunakannya bahasa Arab sebagai bahasa administratif. Oleh karena itu, masyarakat Koptik pun dituntut untuk mempelajari bahasa Arab (Marsot, 2007).

Selain itu, proses Arabisasi di Mesir terjadi karena adanya migrasi bangsa Arab ke Mesir. Bangsa Arab itu sendiri telah lama dikenal oleh penduduk Kristen Mesir. Pada 610 SM, terdapat sejumlah komunitas Arab yang menetap di Alexandria. Namun setelah penaklukkan Mesir oleh bangsa Arab, telah terjadi migrasi besar-besaran bangsa Arab utamanya dari Semenanjung Arab ke Mesir yang disebabkan oleh beberapa faktor: 1) terdapat jumlah kelahiran yang tinggi di kalangan migran Arab; 2) para penguasa Mesir yang ditunjuk oleh Khalifah, datang ke Mesir disertai dengan pasukannya. Para migran Arab ini banyak menguasai ladang-ladang sawah dan langsung berbaur dengan mayarakat lokal. Selanjutnya, terjadi proses pernikahan dengan penduduk lokal yang mengakibatkan semakin kokohnya integrasi antara migran Arab dengan penduduk lokal (Ibrahim, 1995; Mikhail, 2003).

Bahasa Arab menjadi bahasa resmi negara di Mesir terjadi pada abad ke-8 M (Osman, 2010). Meskipun demikian, kalangan Koptik - khususnya mereka yang bekerja di pemerintahan-memiliki peranan penting untuk menyebarkan 
bahasa Arab karena: 1) mengikuti surat keputusan pemerintah yang menetapkan bahwa seluruh badan pemerintahan wajib mendukung program Arabisasi. Oleh karena itu, para pegawai Koptik pemerintah harus belajar bahasa Arab; 2) dikarenakan adanya tradisi "Fir' aun" yaitu tentang mewariskan pekerjaan bagi anggota keluarga, maka para pegawai pun mengajarkan bahasa Arab kepada keluarga mereka untuk menyelamatkan masa depan generasi mereka; 3) hubungan pemerintah dengan masyarakat lokal yang terjadi setiap hari menuntut kedua belah pihak untuk menguasai bahasa Arab; 4) pemerintahan Islam secara berturut-turut memperlihatkan sikap toleran dan hal ini dengan sangat baik diterima oleh Koptik. Sejak pemerintahan Fatimiah, para pejabat Senior Koptik telah mulai menggunakan nama dan gelar Arab; dan 5) dorongan utama penggunaan bahasa Arab di kalangan Koptik adalah ketika Pope Gabriel (1131-1145 M) mengeluarkan Dekrit Papal yang untuk pertama kalinya dalam sejarah Gereja, yaitu anjuran untuk menggunakan bahasa Arab dalam seluruh pelayanan Gereja. Dekrit ini dikeluarkan mengingat sudah semakin sedikitnya jama'ah yang mampu memahami ritual Gereja dalam bahasa Koptik (Ibrahim, 1995).

Penyebaran bahasa Arab ke pelbagai belahan dunia Arab dan Timur Tengah (termasuk Mesir) bersamaan dengan penyebaran Islam mengalami proses akulturasi dan asimilasi dengan budaya lain. Oleh karena itu, lahirlah tuntutan akan adanya standarisasi bahasa Arab yang didasarkan pada tiga alasan berikut: 1) perbedaan bahasa Fuṣha dengan bahasa pasaran (colloquial) menjadi ancaman serius dalam proses komunikasi; 2) kebijakan pemerintahan pusat, mulai dari Damascus era Umayyah dan berikutnya di Baghdad era Abbasiah, berupaya melakukan kontrol dalam berbagai bidang termasuk bahasa Arab; 3) perubahan situasi yang begitu cepat diiringi dengan munculnya berbagai kosakata baru menuntut adanya standarisasi
(Versteegh, 1997). Maka, pusat kreativitas literer bahasa Arab pun bergerak dari kota-kota oasis ke kota-kota baru yaitu Barsah, Kufah, dan Baghdad. Dari kotakota inilah kemudian lahir para linguis dan sastrawan Arab mulai dari Sibawaih (w. 793), Ibn Qutaibah (828-889 M), dan al-Mutanabbi (915-968) (Hourani, 1992).

Bahasa Arab pada perkembangan berikutnya baik itu di Mesir maupun Dunia Arab pada umumnya, selain berfungsi sebagai bahasa al-Qur'an namun dengan menguatnya gerakan panArabisme utamanya pada era tahun 1940an, bahasa Arab menjanjikan keberlangsungan sejarah intelektual Arab, di samping itu dapat menyatukan dunia Arab, dan menjadi senjata kolektif menentang kolonialisme (Haeri, 1997). Dalam proses demikian, kalangan Koptik dan minoritas lainnya seperti telah disebutkan pada uraian sebelumnya banyak terlibat dalam gerakan atau ideology iyang mendasarkan pada identitas kultural Arab.

\section{Pengaruh Bahasa Arab Pada Aspek Sosio-Kultural Koptik}

Sebuah teks berbahasa Arab yang berjudul Apocalypse of Samuel of Qalamun barangkali dapat dikatakan sebagai satu-satunya naskah yang berhasil menceritakan tentang language change di antara kalangan Koptik, yaitu dari bahasa Koptik ke bahasa Arab. Bukan itu saja, teks ini pun menceritakan tentang kekecewaan dan kegelisahan kalangan elit Koptik dengan apa yang terjadi pada komunitas mereka (Zaborowski, 2008). Asal-usul mengenai teks Qalamun ini apakah aslinya memang menggunakan bahasa Arab atau Koptik masih menjadi perdebatan di kalangan akademisi. Berikut adalah salah satu kutipan dari teks tersebut seperti yang dikutip oleh Jason R. Zaborowski dalam papernya yang berjudul From Coptic to Arabic in Medieval Egypt(hal. 37): 


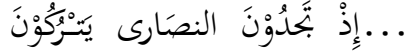

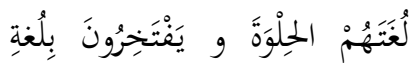

$$
\begin{aligned}
& \text { العربية و بأسمائِهم... } \\
& \text { “...kamu menyaksikan } \\
& \text { bahwa orang-orang Nasrani, } \\
& \text { mulai meninggalkan bahasa } \\
& \text { mereka yang indah [bahasa } \\
& \text { Koptik], kemudian } \\
& \text { membanggakan bahasa } \\
& \text { Arab serta mulai } \\
& \text { menamakan diri dengan } \\
& \text { bahasa Arab..." }
\end{aligned}
$$

Berdasarkan kutipan di atas, hal pertama kali yang terjadi atas pengaruh bahasa Arab terhadap komunitas Koptik dari sisi identitas adalah bahasa itu sendiri, yaitu proses language change yang terjadi dari Koptik ke Arab. Selain itu juga, pergantian nama diri dengan bahasa Arab. Menurut Mikhail, namanama Arab yang paling populer digunakan oleh kalangan Koptik adalah nama Abdullah dan Sa'id. Hal ini dapat menunjukkan pada dua hal, pertama dengan nama tersebut mereka berkonversi menjadi pemeluk Islam atau tetap sebagai penganut Koptik namun menggunakan nama Arab dengan tujuan agar lebih mudah membaur dengan kalangan Muslim (Mikhail, 2003). ${ }^{3}$

Teks Qalamun yang penulis kutip langsung dari sumber aslinya https://archive.org/details/TheApocalypse OfSamuelOfKalamun, diketik ulang apa adanya tanpa ada modifikasi sedikit pun dari sisi bahasa mengingat sebagian redaksi bahasanya belum sesuai dengan bahasa Arab standar. Berikut sebagian

\footnotetext{
${ }^{3}$ Terdapat catatan tambahan menarik lainnya bahwa selama pemerintahan Turki Usmani, banyak dari kalangan Koptik Mesir yang dengan sengaja meniru gaya hidup kalangan Muslim elit, yaitu mereka secara legal mengadopsi pernikahan poligami dan memiliki banyak budak (Afifi, 1999). Tentunya, pernikahan poligami ini tidak sejalan dengan doktrin Kristiani yang sesungguhnya.
}

dari kutipan teks Qalamun yang menceritakan tentang language change yang terjadi ketika itu:

$$
\begin{aligned}
& \text {...الآقوِيا فِن معرفِة اللهِ الذين لغة } \\
& \text { [اللغة] القِبطيّة حسنةٌ فن آفواهِهْم } \\
& \text { مثلُ ححأوةِ العسَلِ فائحةٌ منهم مثلُ }
\end{aligned}
$$

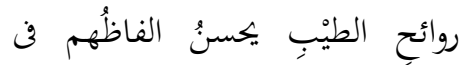

$$
\begin{aligned}
& \text { القبطيةِ و كلّهمْ فن ذلك الزمانِ }
\end{aligned}
$$

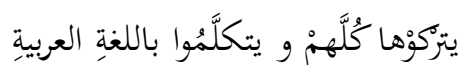

$$
\begin{aligned}
& \text { و تَفتخِروٌا بها حتى اهَّمْ لا يعرفوا البتّةَ } \\
& \text { اكّمْ نصَارَى.... } \\
& \text {...Yang paling kuat } \\
& \text { memahami Tuhan adalah } \\
& \text { mereka yang mulutnya } \\
& \text { berucap dengan [Bahasa] } \\
& \text { Koptik, manis bagaikan } \\
& \text { madu dan harum bagaikan } \\
& \text { parfum. Kebaikan itu karena } \\
& \text { pelafalan mereka dalam } \\
& \text { bahasa Koptik. Pada saat ini, } \\
& \text { mereka meninggalkan } \\
& \text { bahasa Koptik, mulai } \\
& \text { berbicara dengan bahasa } \\
& \text { Arab dan merasa bangga } \\
& \text { dengannya. Mereka lupa } \\
& \text { bahwa mereka adalah } \\
& \text { Kristen. }
\end{aligned}
$$

Teks di atas menjelaskan bahwa persoalan language change yang terjadi dari bahasa Koptik ke bahasa Arab dipandang sebagai persoalan yang sangat serius. Hal ini dikarenakan bahasa Koptik merupakan sacred language, bahasa suci yang digunakan untuk liturgi dan juga kitab suci. Di samping itu, berbangga diri dengan bahasa Arab dalam penjelasan di atas menunjukkan bahwa mereka telah melupakan identitas Koptik yang sesungguhnya yaitu sebagai penganut Kristiani.

Di sisi lain, pengaruh bahasa Arab terhadap identitas kultural lainnya utamanya dapat dilihat dari proses integrasi diri mereka sebagai bagian dari identitas Mesir yang baru (dengan Agama Islam dan bahasa Arab). Kenyataan 
bahwa proses Arabisasi tidak dapat dihindarkan lagi maka satu-satu cara yang dapat mereka lakukan adalah menjadi bagian dari pada kebudayaan baru tersebut. Oleh karena itu, masyarakat Koptik melihat bahwa hanya ada satu cara agar mereka bisa berintegrasi dengan masyarakat Mesir yang mayoritas Muslim itu, yaitu dengan cara membangun identitas kultural pada ke-Arabannya (the Arabness) dengan meninggalkan sebagian elemen kultural mereka lainnya, yaitu bahasa Koptik. Ini adalah momen di mana bahasa Koptik seperti dikemukakan sebelumnya sebagai

a dying language, bahasa yang sedang menemui ajalnya.

Imbas dari pada proses ini maka muncullah tokoh atau intelektual Koptik yang mencoba membangun teori integrasi kultural yang menekankan bahwa Koptik merupakan bagian dari Mesir dengan identitas barunya itu (the Arabness). Maka meskipun pada awal mulanya elit Koptik menolak identitas Arab dengan segala komponennya (Agama dan bahasa), namun pada akhirnya mereka harus mengakui identitas Arab sebagi komponen kultural mereka yang baru. Oleh karena itu, muncullah pengakuan bahwa Mesir dengan ke-Arabannya merupakan bagian dari identitas Koptik yang baru.

Berikut beberapa statemen yang disampaikan oleh tokoh-tokoh Koptik tentang integrasi Koptik ke dalam kultur Arab dalam konteks negara Mesir. Paus Shenouda mengemukakan bahwa "Mesir sebagai anak dari bumi yang satu" dan William Soliman Kelada, seorang inteletkual Koptik menyebutkan bahwa ketika terjadi perang antara Mesir melawan Israel pada 1973 M, para tentara Koptik bahkan ikut berpuasa Ramadhan sebagai bentuk penghormatan terhadap rekan mereka yang Muslim, bahkan para pemimpin tentara sesekali mengutip alQur'an dan Injil sebagai motivasi dalam peperangan. Milad Hanna seorang Koptik berprofesi sebagai kolumnis koran mencatat bahwa Mufti al-Azhar, yaitu
Muhammad Sa'id Tantawi bahkan memiliki pembantu rumah tangga seorang Koptik dengan dua isterinya (Sedra, 1999).

Integrasi Koptik sebagai entitas Mesir memang sangat kuat dan memiliki akar historisnya. Menurut Milad Hanna dalam Paul Sedra (1999), menyebutkan bahwa terdapat tujuh pilar identitas Mesir yang tidak dapat dipisahkan yaitu: 1) Mesir merupakan warisan budaya Fir'aun (dengan warisan budaya dan peradabannya seperti Piramida dan lainlain), 2) Mesir merupakan warisan peradaban Yunani-Roma, 3) secara historis penduduk asli Mesir adalah Koptik, 4) Islam sebagai agama mayoritas, 5) Arab sebagai bahasa dan identitas, 6) Mesir merupakan wilayah Meditarian, dan 7) Mesir sebagai bagian dari Afrika (Sedra, 1999).

Secara ideologis, wujud integrasi Koptik dalam identitas Mesir dan kebudayaan Arab pada umumnya terwujud dalam Pan-Arabisme yang digagas oleh Nasser. Dan salah satu pilar dari Pan-Arabisme adalah persatuan Arab yang didasarkan pada identitas bahasa, yaitu bahasa Arab. Sebagai penguasa asli pribumi pertama dalam sejarah Mesir modern, Nasser mampu menghadirkan kepentingan politik nasional dengan tidak mengedepankan perbedaan agama. Identitas Koptik yang telah menyatu dengan Arab-Mesir memandang programprogram nasional Nasser sangat inklusif dan sesuai dengan warisan Arab-Mesir (Osman, 2010).

Semua narasi di atas hanya untuk mengukuhkan klaim bahwa kekalahan bahasa Koptik dari bahasa Arab yang kemudian menjadi proses transformasi kultural Koptik ke dalam identitas baru hanya bisa diatasi dengan cara menjadi bagian dari proses transformasi kultural di atas. Di samping itu, karena secara pragmatis bahasa Koptik tidak dapat digunakan lagi maka memilih bahasa Arab adalah pilihan yang secara ekonomis, politik, 
dan kultural merupakan pilihan yang tetap meskipun pada awalnya sulit diterima karena bahasa Koptik bukan hanya sekedar bahasa komunikasi tetapi juga sebagai sacred language. Maka, bagian berikutnya akan melihat lebih jauh dampak dari bahasa Arab pada aspek keagaaman Koptik.

\section{Pengaruh Bahasa Arab Pada Aspek Agama Koptik}

Penjelasan tentang proses Arabisasi yang terjadi di Mesir tidak serta merta diiringi dengan proses konversi secara penuh (perpindahan agama dari Koptik menjadi Islam). Maksud dari penjelasan ini seperti yang dikemukakan oleh Mikhail adalah bahwa Arabisasi dan konversi adalah dua hal yang berbeda. Bahasa Arab sebagai bahasa komunikasi memang telah menghapus bahasa Koptik di Mesir. Meskipun demikian, masih terdapat masyarakat Koptik $^{4}$ yang mempertahankan keyakinan mereka sampai sekarang ini meskipun mereka sudah sepenuhnya mengadopsi bahasa Arab (Mikhail, 2003). Oleh karena itu, bahasa Arab pada level tradisi agama Koptik hanya berlaku sebagai"medium"untuk memahami literatur agama seperti Injil dan juga ritual ibadah lainnya. Hal ini seperti halnya dulu pernah terjadi ketika mereka harus mengadopsi kosa-kata Yunani ke dalam bahasa Koptik saat terjadi proses Kristenisasi di Mesir.

Imbas dari adanya proses Arabisasi dan formalisasi bahasa Arab di Mesir juga Timur Tengah pada umumnya adalah

\footnotetext{
${ }^{4}$ Mereka yang masih mempertahankan agama mereka (Kristen) tetap disebut sebagai Koptik (dalam komunikasi harian mereka secara umum disebut Masihi) dan tidak berlaku bagi mereka yang sudah menjadi Muslim. Jadi, penyebutan Koptik itu secara khusus untuk menegaskan mereka yang Kristen-Koptik saja bukan penduduk Mesir Kristen Katolik atau pun Protestan.
}

kebutuhan terhadap literatur agama berbahasa Arab utamanya kitab Injil. Meskipun demikian, proses penerjemahan Injil atau kitab liturgi lainnya dari bahasa Koptik ke dalam bahasa Arab terjadi belakang. Penerjemahan Injil ke dalam
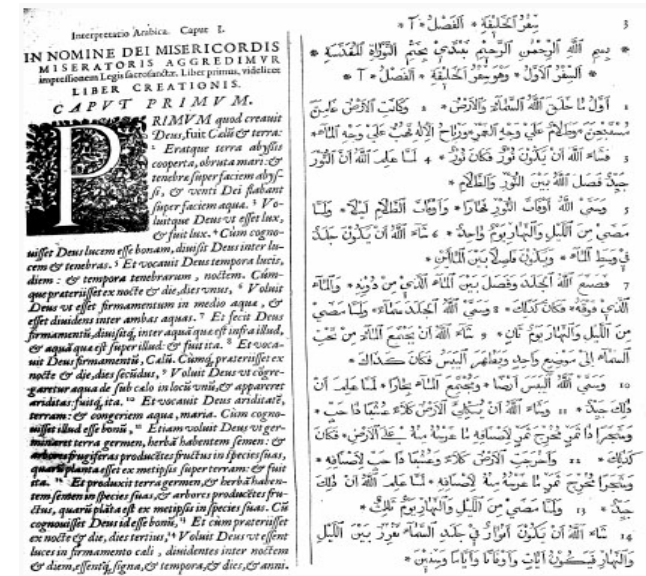

bahasa Arab untuk pertama kalinya justru berasal dari Injil berbahasa Suryani, Injil berbahasa Yunani, dan Injil dari bahasa Ibrani (Griffith, 2013). Dalam tradisi penerjemahan berikutnya, aktifitas penerjemahan kitab-kitab Suci ke dalam bahasa Arab justru banyak dilakukan oleh kalangan Yahudi, khususnya dilakukan oleh sekte Karaite (Polliack, 1996). Penerjemahan Injil dari bahasa Ibrani ke bahasa Arab terjadi pada abad ke-9 M (Hall, 1885). Berikut adalah gambar salah satu contoh Injil berbahasa Arab yang diterjemahkan dari bahasa Ibrani:

Gambar 2.Injil berbahasa Arab dengan bahasa sumber Ibrani. Diterjemahkan oleh Sa'adyah HaGaon (Sumber: Griffith, 2013).

Dari sisi penerjemahan Arab, Gambar 2 menunjukkan bahwa teks Injil di atas pada baris ke-2 diawali dengan frasa Bismillāhirrahmōnirrahīm, sebuah frasa yang sangat familiar dalam tradisi Islam. Barangkali temuan ini menjadi temuan menarik apakah frasa Bismillōhirrahmōnirrahīm merupakan frasa milik umat Islam atau sudah ada sebelum Islam lahir, sehingga diadopsi dalam penerjemahan Injil seperti dalam penggalan teks di atas.

Di Mesir sendiri, penerjemahan Injil pada mulanya juga bersumber dari 
Injil berbahasa Yunani atau disebut dengan Septuagint, diterjemahkan oleh seorang filsuf Nestorian bernama Hunain Ibnu Ishaq. Pada abad ke-13 M, Koptik memiliki beberapa versi terjemahan Injil dalam bahasa Arab. Koptik sendiri berhasil memiliki teks Injil Arab sekitar paruh kedua abad ke-11 M. Injil versi Arab yang dipakai oleh Koptik adalah hasil terjemahan abad ke-11 M oleh Abu al-Fath 'Abd Allah ibn Fadl. Injil berbahasa Arab abad ke-10 M atau atau dikenal dengan Vulgata Mesir/Alexandria merupakan hasil terjemahan dari teks Buhairic, yaitu Injil yang ditulis dengan salah satu dialek Koptik-Mesir (Meinardus, 2002).

Meskipun Injil berbahasa Arab sudah ada sejak abad ke-7 M, namun versi cetakan pertamanya adalah Injil berbahasa Arab versi Paris dan London Poliglot. Kitab Perjanjian Lama berbahasa Arab diamankan oleh Francis Savary de Brèves di Kairo pada tahun 1606 M, dan Injil berbahasa Arab versi London Poliglot muncul dua dekade kemudian. Pada tahun 1876 dan $1878 \mathrm{M}$, terdapat Injil berbahasa

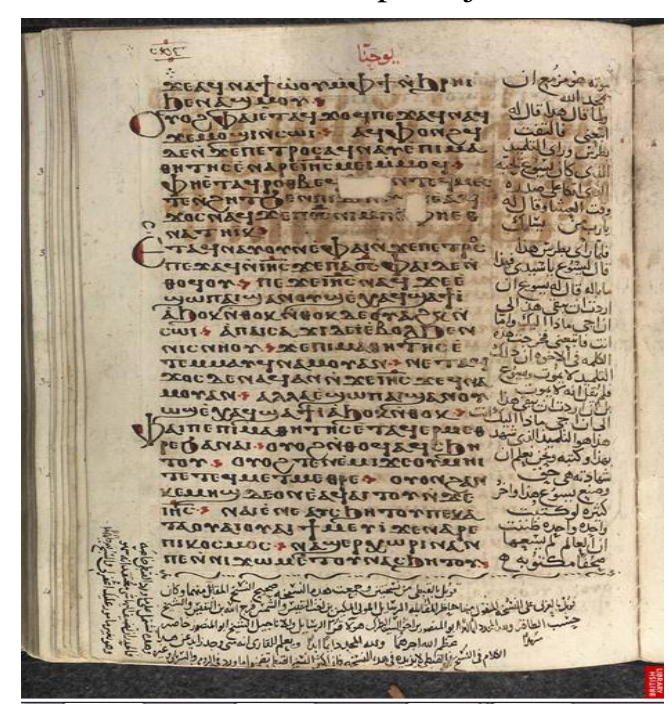

Arab versi Jesuit yaitu al-Kit $\bar{\alpha} b$ alMuqaddas yang diterbitkan di Beirut. Juga terdapat Injil dalam bahasa Arab hasil karya terjemahan Smith-Van Dyck tahun 1965. Kalangan Koptik menggunakan Injil berbahasa Arab versi Jesuit dan versi Smith-Van Dyck (Meinardus, 2002).
Secara khusus, berdasarkan penelusuran penulis secara online, ditemukan Bible dalam bahasa Koptik yang disertai terjemahan Arab di sampingnya. Manuskrip berikut merupakan koleksi dari British Library yang ditampilkan secara online, itu pun hanya satu halaman saja.

Gambar 3. Injil dalam Koptik dan Arab (Sumber: http://www.bl.uk

Menurut catatan sejarahnya, manuskrip di atas merupakan bagian dari Empat Injil yang dibuat pada tahun 1663 M. Injil di atas merupakan Injil versi Yohanes. Manuskrip tersebut diberi kode koleksi BL Or. 425 , f.116v, yang tersimpan di galeri British Library http://www.bl.uk/onlinegallery/sacred texts/gospelsarabic.html.

Masih terdapat foto-foto lain terkait dengan Injil Koptik yang dilengkapi dengan terjemahan Arab yang terdapat di beberapa situs online linnya, namun secara umum dokumen menampilkan manuskrip yang sama dengan halaman yang berbeda. Hanya saja, karena dokumen tersebut adalah dokumen yang langka, maka sekali lagi hanya beberapa bagian saja yang dapat diakses gratis secara online.

Dalam perkembangan keagamaan Koptik kontemporer seiring dengan menguatnya akan kesadaran identitas sejarah Koptik masa lalu, terdapat gerakan-gerakan yang berupaya untuk menghidupkan kembali bahasa Koptik khususnya untuk kegiatan ritual keagamaan mereka. Gerakan ini dipelopori oleh kalangan anak muda Koptik yang menamakan diri mereka dengan The Sunday School Movement (Hasan, 2003; Henderson, 2005). Namun secara umum, Koptik di Mesir masih menggunakan bahasa Arab sepenuhnya dalam pelaksanaan liturgi dan ibadah ritual seperti sembahyang, berdo'a, dan juga resepsi pernikahan. Jadi, untuk mengembalikan bahasa Koptik ke dalam 
tradisi agama mereka tidak lah mudah karena bahasa Arab sudah mengakar kuat dan menjadi bagian integral kebudayaan mereka.

\section{SIMPULAN}

Dari uraian tentang pengaruh bahasa Arab terhadap identitas sosiokultural dan keagamaan Koptik di Mesir dapat ditarik dua kesimpulan utama berikut. Pertama, pada level sosio-kultural pengaruh bahasa Arab terhadap identitas Koptik untuk pertama kalinya adalah penggunaan bahasa Arab itu sendiri yang secara formil digunakan pada ke-8 $\mathrm{M}$ dan menggantikan bahasa Koptik. Indikator utamanya adalah pergantian nama diri dari bahasa Koptik ke Arab. Imbas dari adanya pergeseran bahasa (language change) ini maka kemudian bahasa Arab diadopsi menjadi bagian integral dari identitas kultural mereka yang baru.

Kedua, pada level keagamaan yang paling terlihat adalah penerjemahan Injil dari bahasa Koptik ke dalam bahasa Arab. Meskipun penerjemahan awal bukan dari bahasa Koptik, namun hal ini menunjukkan betapa bahasa Arab telah berimbas pada penerjemahan kitab suci meraka. Padahal, bahasa Koptik seperti yang tertera dalam dokumen Qalamun, dianggap sebagai sacred language dan menggunakan bahasa Arab bagi kalangan Koptik pada awal mulanya dianggap menyalahi tradisi Kristiani. Namun pada akhirnya, penolakan terhadap penggunaan bahasa Arab tidak dapat dihindari lagi saat berhadapan dengan kenyataan bahwa generasi muda Koptik tidak lagi mampu memahami bahasa asli mereka dan lebih memilih bahasa Arab sebagai pilihan rasional. Selain dari sisi kitab Suci, bahasa Arab pun digunakan dalam ritual-ritual ibadah lainnya seperti pernikahan di gereja dan lain-lain.

\section{DAFTAR PUSTAKA}

\section{Jurnal dan Buku}

Afifi, M. (1999). The state and the church in nineteenth-century Egypt. Welt Des Islams, 39, 273-288.
Armanios, F. (2011). Coptic Christianity in Ottoman Egypt. Oxford University Press.

Brockelmann, C. (1947). History of the Islamic Peoples, trans. J. Carmichael and M. Perlmann (New York, 1960) (Vol. 98).

Chaillot, C. (2009). The life and situation of the Coptic Orthodox church today. Studies in World Christianity, 15(3), 199-216.

Coptic alphabet, pronunciation and language. (n.d.). Retrieved December 8, 2017, from http://www.omniglot.com/writing/co ptic.htm

Elyas, P. V. (2012). No Longer Dhimmis: How European Intervention in the Nineteenth and Early Twentieth Centuries Empowered Copts in Egypt.

Goldschmidt Jr, A., \& Boum, A. (2015). A concise history of the Middle East. Hachette UK.

Gregorius, B. (1982). Christianity, the Coptic religion and ethnic minorities in Egypt. GeoJournal, 57-62.

Griffith, S. H. (2013). The Bible in Arabic: The Scriptures of the'People of the Book'in the Language of Islam. Princeton University Press.

Guirguis, M. (2012). The Copts and the Egyptian Revolution: Various Attitudes and Dreams. Social Research, 79(2), 511-530.

Haeri, N. (1997). The reproduction of symbolic capital: Language, state, and class in Egypt. Current Anthropology, 38(5), 795-816.

Hall, I. H. (1885). The Arabic Bible of Drs. Eli Smith and Cornelius V. A. Van Dyck. Journal of the American Oriental Society, 11, 276-286. https://doi.org/10.2307/592194

Hasan, S. S. (2003). Christians versus Muslims in modern Egypt: The 
century-long struggle for Coptic equality. New York: Oxford University Press.

Hatina, M. (2006). In search of authenticity: a Coptic perception. Middle Eastern Studies, 42(1), 4965.

Henderson, R. P. (2005). The Egyptian Coptic Christians: the conflict between identity and equality. Islam and Christian-Muslim Relations, 16(2), 155-166.

Hourani, A. (1962). Arabic thought in the liberal age 1798-1939. Cambridge University Press.

Hourani, A. (1992). A History of The Arab Peoples. New York: Cambridge: Belknap Press of Harvard University Press.

Ibrahim, S. E. (1995). The Copts of Egypt. Minority Rights Group.

Jirjis, M. (2008). An Armenian Artist in Ottoman Egypt: Yuhanna Al-Armani and His Coptic Icons. American Univ in Cairo Press.

Lewis, B. (1998). The Multiple Identities of the Middle East. New York: Schocken.

Marsot, A. L. al-S. (2007). A history of Egypt: from the Arab conquest to the present. Cambridge University Press.

Mayton, J. (2006). A Dying Language. The Middle East, pp. 60-61.

Meinardus, O. F. A. (2002). Two thousand years of Coptic Christianity. Cairo: American Univ in Cairo Press.

Mikhail, M. S. A. (2003). Egypt from late antiquity to early Islam: Copts, Melkites, and Muslims shaping a new society.

Mohamoud, Y. A., Cuadros, D. F., \&
Abu-Raddad, L. J. (2013). Characterizing the Copts in Egypt: Demographic, socioeconomic and health indicators. QScience Connect, 22.

Osman, T. (2010). Egypt on the Brink: from Nasser to Mubarak. Yale University Press.

Polliack, M. (1996). The Medieval Karaite Tradition of Translating the Hebrew Bible into Arabic: Its Sources, Characteristics and Historical Background. Journal of the Royal Asiatic Society, 6(2), 189196. Retrieved from http://www.jstor.org/stable/2518318 0

Rahman, T. (2002). Language, power and ideology. Economic and Political Weekly, 4556-4560.

Sedra, P. (1999). Class cleavages and ethnic conflict: Coptic Christian communities in modern Egyptian politics. Islam and Christian-Muslim Relations, 10(2), 219-235.

Versteegh, K. (1997). The Arabic Language. New York: Columbia University Press.

Zaborowski, J. R. (2008). From Coptic to Arabic in Medieval Egypt. Medieval Encounters, 14(1), 15-40.

\section{Website}

http://www.bl.uk/onlinegallery/sacredtext s/gospelsarabic.html, accessed 10 December 2017

http://www.omniglot.com/writing/coptic.h tm. accessed 10 December 2017.

https://archive.org/details/TheApocalypse

OfSamuelOfKalamun, accessed 7

